\title{
Matética, pedagogia e o papel que ainda não têm nos estudos curriculares
}

\author{
Carlos Nogueira Fino*
}

\section{Resumo}

$\mathrm{O}$ artigo procura compreender a razão pela qual Pinar (2005) considera que a pedagogia (pedagogy) e o papel dos professores beneficiam de um estatuto inflacionado nos estudos curriculares, que precisa de ser ajustado (apesar da dificuldade da tarefa), sendo a chave dessa compreensão o significado de pedagogia na cultura anglo-americana. Com a ajuda de Hamilton (1993, 1999), o artigo estabelece uma relação entre pedagogia e didática, respetivamente nas culturas anglo-americana e europeia. Como exemplo para a compreensão do que é pedagogia, apresenta-se o construcionismo de Papert, mostrando como ela pouco tem a ver com didática, tornando evidente que, caso Pinar se tivesse exprimido em língua portuguesa, teria considerado que o que está efetivamente inflacionado nos estudos curriculares é a didática, devendo essa inflação ser corrigida.

Palavras-chave: Matética, Pedagogia, Estudos Curriculares.

* Professor Catedrático (Full Professor). Presidente da Faculdade de Ciências Sociais e responsável pela linha de pesquisa em inovação pedagógica do Centro de Investigação em Educação (CIE-UMa) da Universidade da Madeira, Portugal. cfino@staff.uma.pt 


\section{Mathetics, pedagogy and the role they do not yet have in curriculum studies}

\section{Matética, pedagogía y el papel que aún no tienen en los estudios curriculares}

\section{Abstract}

The article seeks to understand why Pinar (2005) considers that pedagogy and the role of teachers benefit from an inflated status in curriculum studies, which needs to be adjusted (despite the difficulty of the task), being the key to this understanding the meaning of pedagogy in Anglo-American culture. With the help of Hamilton (1993, 1999), the article establishes a relationship between pedagogy and didactics, respectively in Anglo-American and European cultures. As an example for the understanding of what is pedagogy, Papert's constructionism is addressed, showing how it has little to do with didactics, and making it evident that, had Pinar expressed himself in Portuguese, he would have considered that what is effectively inflated in curriculum studies is didactics, and this inflation should be corrected.

Keywords: Mathetics, Pedagogy, Curriculum Studies.

\section{Resumen}

El artículo trata de comprender la razón por la que Pinar (2005) considera que la pedagogía y el papel de los profesores se benefician de un estatus inflacionado en los estudios curriculares, que necesita ser ajustado (a pesar de la dificultad de la tarea), siendo la clave de esa tarea comprender el significado de la pedagogía en la cultura angloamericana. Con la ayuda de Hamilton (1993, 1999), el artículo establece una relación entre pedagogía y didáctica, en las culturas anglo-americana y europea. Como ejemplo para la comprensión de lo que es pedagogía, se presenta el construccionismo de Papert, mostrando como esa pedagogía poco tiene que ver con didáctica, haciendo evidente que, si Pinar se hubiera expresado en lengua portuguesa, habría considerado que lo que está efectivamente inflado en los estudios curriculares es la didáctica, debiendo corregirse esta inflación.

Palabras clave: Matética, Pedagogía, Estudios Curriculares. 
1.

A iniciar a sua obra monumental, Didactica Magna, ou Tratado da Arte Universal de Ensinar Tudo a Todos, Comenius fazia a seguinte advertência sobre o seu propósito:

A proa e a popa da nossa Didática será investigar e descobrir o método segundo o qual os professores ensinem menos e os estudantes aprendam mais; nas escolas, haja menos barulho, menos enfado, menos trabalho inútil, e, ao contrário, haja mais recolhimento, mais atrativo e mais sólido progresso; na Cristandade, haja menos trevas, menos confusão, menos dissídios, e mais luz, mais ordem, mais paz e mais tranquilidade $^{2}$.

Como é evidente, a aplicação do princípio de ensinar menos, para que os estudantes aprendam mais, tem uma consequência óbvia: enquanto mingua a atividade de quem ensina, deve aumentar a de quem aprende. A este propósito, refira-se que o desenvolvimento da arte de ensinar, sendo o mais conhecido, não foi o único objetivo de Comenius, que dedicou grande parte da sua última obra, intitulada Spicilegium Didacticum, à Matética, palavra quase desaparecida do discurso atual da educação, definindo-a como a arte do discente, na sua tarefa de aprender a procurar e conhecer a ciência das coisas.

Portanto, a contribuição de Comenius esteve longe de se esgotar na didática propriamente dita, completando-a com a consideração do seu contrário, a matética, e fundando no desequilíbrio entre ambas, em benefício da matética, aquilo que me parece ser o verdadeiro sentido do seu legado, independentemente do que foi feito dele ao longo do tempo. Com efeito, o passar do tempo trouxe-nos a inversão desse desequilíbrio a favor dos procedimentos didáticos, muito por causa do tipo de escola que emergiu durante a industrialização. Como se sabe, esse tipo de escola e o seu modelo de organização curricular disseminaram-se por todo o mundo durante a industrialização, visando apoiar a expansão da nova economia através do estabelecimento de uma meritocracia competitiva e da preparação dos trabalhadores para os seus papéis no mundo do trabalho.

Como sabemos, esse tipo de escola foi sendo asperamente criticado por gerações de pedagogos, nomeadamente pelos partidários da educação progressista, que o consideravam contrário ao que o conhecimento científico ia revelando, desde os finais do séc. XIX, sobre a natureza da criança, sobretudo no que se refere à relação entre a atividade e a cognição. Como também sabemos, o tipo de escola, passiva e massificada, tão criticada por esses pedagogos, pouco devia à ciência, inexistente ou incipiente no momento em que o método de instrução simultânea se generalizou, ainda na primeira metade do séc. XIX. De facto, esse tipo de escola era muito mais devedor da política, da economia e do senso comum, do que propriamente da ciência, tivesse ela sido a psicologia, a sociologia, ou qualquer outra.

No que diz respeito à dicotomia didática-matética, os partidários da educação progressista, se os tivéssemos de considerar sob esse ponto de vista, teriam sido bastante mais adeptos da segunda do que da primeira. $\mathrm{E}$, defensores que eram do direito das crianças serem crianças e serem ativas, esforçar-se-iam, creio, por limitarem ao mínimo as suas ações didáticas, para darem espaço ao protagonismo matético dos seus aprendizes.

No entanto, Pinar (2005), também deteta uma inflação do papel dos professores entre os partidários da educação progressiva, e reclama a necessidade de ajustar o estatuto inflacionado que a pedagogia entretanto adquiriu no âmbito dos estudos curriculares:

Despite its very different politics, progressive education also inflated the role of the teacher in the process of education, suggesting that role could be socially transformative. Adjusting the inflated status of pedagogy in curriculum studies will be difficult but necessary labor. (PINAR, 2005, p. 2)

O artigo de Pinar não tem a preocupação de debater o que o seu autor entende por pedagogia, embora se 
possa assumir que o significado que lhe atribui não será muito distante de "science of teaching". Esta convicção tem presentes a tradição de racionalização e simplificação introduzida pela didática, no séc. XVII, que enfatiza o papel do professor, a ideia novecentista de educação como ciência, e a memória mais recente da influência da corrente do eficientismo social, inspiradora de Bobbit, por exemplo, que reduziu o ato pedagógico a mera intervenção de natureza técnica.

A este propósito da não discussão e clarificação dos conceitos e referindo-se à tradição britânica, já argumentava Simon (1981, p. 1): "The most striking aspect of current thinking and discussion about education is its eclectic character, reflecting deep confusion of thought, and of aims and purposes, relating to learning and teaching - to pedagogy".

É claro que não estou a criticar Pinar, caso tenha utilizado a palavra pedagogia com aquela conotação, nomeadamente quando o seu propósito explícito era o de reabilitar a antiga noção de estudo (é esse o foco do seu artigo), o qual acabou por ser historicamente suplantado pelo racionalismo reducionista que inventou a didática e que, séculos depois, procurou reduzir a função do professor a um conjunto de rotinas meramente técnicas. O meu objetivo é bem diferente, e consiste numa tentativa de contribuir para a recuperação de um conceito de pedagogia, na minha perspetiva bem mais nobre, que muitas vezes parece estar irremediavelmente perdido. $\mathrm{E}$, ao fazê-lo, procuro refletir na esteira de pedagogos cuja ação transcendeu, de longe, a redução da pedagogia a um conjunto de técnicas aplicadas acriticamente, no âmbito de processos de transmissão de pacotes de conteúdos pré-determinados e pré-organizados.

Esta minha preocupação tem ainda maior urgência numa época de grande e acelerada transformação, impulsionada pelo desenvolvimento tecnológico. Embora aparentemente intocadas nos seus pressupostos essenciais tradicionais (currículo taylorizado e a priori, turmas organizadas por idades cronológicas, enfoque nos resultados muito mais do que nos processos, etc.) as escolas não tiveram outro remédio que abrirem-se às novas tecnologias, cujo aproveitamento didático já tem quase sessenta anos ${ }^{3}$. Essas tecnologias, ao contrário do poder que tiveram para mudarem a maneira como vivemos, como nos relacionamos e, até, como nos representamos, não mudaram para melhor nada de fundamental, que transformasse a essência das escolas. Nem sequer a sua eficiência, mesmo quando utiliza tecnologias cada vez mais avançadas.

Este uso da palavra pedagogia por Pinar, com um significado próximo do que seria uma definição continental europeia de didática, é explicado por Hamilton (1999) pelo foco crescente no ensino na Europa dos séculos XVI e XVII, caracterizado pela preocupação com os processos e os conteúdos da instrução. Esse período terá ficado marcado por cinco elementos essenciais: o surgimento de literatura sobre o método de instrução, dedicada aos professores; o mapeamento do conhecimento existente em programas disciplinares; o aparecimento da noção de currículo; a crescente sobreposição dos significados de pedagogia e de didática; e todos os quatro elementos anteriores expressos como método:

First, a new literature about instruction - directed at schoolteachers - began to diverge from a longstanding literature about upbringing (i.e. for parents, nurses, governors and tutors). Secondly, the world of existing knowledge began to be mapped, giving rise to the notion of a syllabus (which defined the content of instruction). Thirdly, instruction was organised in terms of journeys across the map of knowledge, giving rise to the notion of curriculum (the course of modern schooling). Fourthly, knowledge was organised around a set of upbringing or presentation principles - giving rise to overlapping notions of pedagogics and didactics (the organisation of upbringing and instruction). Finally, these assumptions about the content, course and organisation of schooling were expressed in the notion of method (the delivery of instruction). (HAMILTON, 1999, p. 138) 
2.

Estará, assim, compreendida a razão pela qual Pinar considera inflacionado o papel dos professores, mesmo entre os partidários da educação progressiva, e reclama pelo ajustamento do estatuto inflacionado que a pedagogia terá entretanto adquirido no âmbito dos estudos curriculares. Falando de pedagogia, do interior da sua cultura anglo-americana, Pinar fala daquilo a que, na tradição continental europeia, falamos de didática.

A esse propósito, Hamilton (1999) esclarece que a didática tem uma valoração negativa na mente anglo-americana, por denotar práticas educativas formalistas, que combinam dogma e aborrecimento, que correspondem a fantasmas europeus indesejáveis de um passado educacional pouco atraente. No entanto, continua, a noção de pedagogia não é estranha aos educadores anglo-americanos, tendo reentrado no léxico educacional anglo-americano após 1970, depois de ter ficado eclipsada desde a Primeira Guerra Mundial, mas com um significado muito diferente do que tinha tido antes da Guerra. Atualmente, a palavra pedagogia tem, no universo anglo-americano, um significado muito próximo do significado europeu de didática ${ }^{4}$.

Portanto, Pinar, ao reclamar a diminuição do estatuto da pedagogia nos estudos curriculares, estará a afirmar que os estudos curriculares têm didática a mais e, uma vez que o objetivo do seu texto é recuperar e enaltecer a noção de estudo, subentenderá que os estudos curriculares têm matética, ou arte de aprender, a menos. A ser plausível esta conclusão, não posso deixar de exprimir satisfação, uma vez que há muito tempo que penso e afirmo isso mesmo.

Aliás, reclamar do estatuto empolado da didática nem seria nada de especial em países como Portugal, em que o substantivo pedagogia, apesar da nobreza do seu significado, está em vias de desaparecer do vocabulário educacional vigente, subsistindo apenas, raramente, como adjetivo (pedagógico, pedagógica), que muitas vezes é utilizado impropriamente, em confusão com didático, por exemplo.
Sobre esse empolamento da didática, e consequente desaparecimento ou redução da pedagogia a um conjunto de procedimentos didáticos, refiram-se a legislação estruturante da formação de professores (regime jurídico da habilitação profissional para a docência na educação pré-escolar e nos ensinos básico e secundário), que foi publicada em Portugal na última década. Essa legislação (Decreto-Lei n. ${ }^{\circ}$ 43/2007, de 22 de Fevereiro, da ministra Maria de Lurdes Rodrigues, e Decreto-Lei n. ${ }^{\circ}$ 79/2014, de 14 de maio, revisão do ministro Nuno Crato do diploma de 2007), além de ter derrogado a autonomia universitária no que tange à formação de professores em Portugal $^{5}$, também erradicou a palavra pedagogia do léxico legal. Com efeito, o diploma de 2007 não inclui nenhuma vez essa palavra, mas refere didática nove vezes. Já o diploma de 2014 continua sem falar de pedagogia, mas aumentou as ocorrências da palavra didática para treze.

É inevitável considerar-se que estas imposições com base legislativa não são neutrais nem inconsequentes. Além de reduzirem o discurso, chamemos-lhe educacional, à sua componente mais prática, que é a da transmissão de conteúdos, procuram garantir que os futuros professores exercerão as suas funções de forma meramente técnica, guiados exclusivamente pelas orientações curriculares, pelo que aprenderam sobre a matéria que ensinam e pela maneira que as instituições de formação Ihes disseram que devem ensinar. Assim com essa simplicidade, para que a escola e os professores não se distraiam do seu grande objetivo, que é o de preparar os alunos exatamente para... Para quê, exatamente?

Refira-se que a "morte" da pedagogia, que escorre dos textos legais portugueses sob a forma de única conceção de formação dos professores admitida, e assim transformada em cânone, se propaga através da ação dos apareIhos do estado que vigiam a concretização desses textos, destacando-se entre esses aparelhos a "independente" agência nacional de acreditação e o seu papel de reforçador da ortodoxia. Refira-se, também, que a insistência na didática é acompanhada da negligência quanto a outras componentes da atividade dos discentes e dos docentes, a qual implica uma visão simplista, para dizer o mínimo, do que devem ser os ambientes escolares. 
$\mathrm{E}$, assim, numa cultura em que a didática e os seus procedimentos passaram a ocupar todo o espectro do discurso sobre educação, imagine-se a dificuldade de comunicação e os equívocos quando se trata de falar de pedagogia ou, ainda pior, de inovação pedagógica.

3.

Quanto mais penso em didática e na sua origem e em como a sua evolução foi limitando o campo da matética, mais lamento que ela não tenha adquirido, na cultura onde vivo, a mesma conotação negativa que lhe reconhece Hamilton na cultura anglo-americana, até porque me parece que ele teria razão se as seguintes palavras se referissem a Portugal.

...didactics has a negative valuation in the Anglo-American mind. It denotes formalist educational practices that combine 'dogma' with 'dullness' (Oxford English Dictionary). It conjures up the unwelcome European ghosts of an unattractive educational past. (HAMILTON, 1999, p. 135).

Porque a didática e os seus procedimentos pertencem quase inteiramente a práticas fundamentadas no senso comum, sendo muitíssimo pouco credores da teoria, nomeadamente da parte da teoria que se ocuparia de a situar e questionar as suas relações com a sociedade e o mundo. Estas relações, como é lógico, nunca poderiam ser negligenciadas se estivéssemos a falar de pedagogia. $\mathrm{Na}$ verdade, qualquer pedagogia digna desse nome invocaria valores e discutiria abertamente os propósitos, os meios e o conteúdo de sua ação. Envolveria reflexão sobre a natureza humana de seus destinatários, sobre a sua dignidade, direitos e necessidades, e sobre a forma de os apoiar no seu desenvolvimento cultural e cognitivo. E os métodos que adotasse seriam os que se provassem mais adequados à natureza e à dignidade dos aprendizes, em concreto. Na minha opinião, qualquer docente que faça verdadeiramente jus a esse nome deve esforçar-se por se transformar em pedagogo e não em didata, especialista numa didática específica e desconhecedor assumido de todas as restantes. E talvez, assim, o modelo de edu- cação que conhecemos fosse diferente daquilo em que se tornou: uma monotonia governada por um currículo cada vez mais supranacional, que faz com que uma escola situada seja onde for seja idêntica a uma escola, não importa em que qualquer outra parte do mundo.

Para ilustrar o que afirmo, gostaria de convocar o exemplo do construcionismo de Seymour Papert, de entre as propostas pedagógicas verdadeiramente importantes e singulares, que surgiram nas últimas décadas, pelo facto de o construcionismo conjugar alguns dos elementos com maior potencial para atenderem às necessidades $\mathrm{e}$ aos interesses dos aprendizes do século atual. Essa pedagogia envolve o construtivismo, como explicação da génese e dos fenómenos da cognição; a ênfase na matética; o domínio sobre as tecnologias digitais, que são as ferramentas mais poderosas de mudança com que vamos precipitando o futuro; e a perspetiva crítica, que habilita uma compreensão distanciada e empenhada da realidade em que vivemos, incluindo a escola.

O construcionismo é uma pedagogia que parte do construtivismo piagetiano, o qual olha para a criança como construtora das suas estruturas cognitivas, em interação com o mundo. Essa pedagogia nega a crença comum, instituidora da didática, segundo a qual o caminho para uma melhor aprendizagem passa pelo aperfeiçoamento da instrução. Recusa, portanto, a convicção de que a escola será melhor se ensinar melhor. Papert (2008), sem pretender negar o valor da instrução em si mesma, mas reconhecendo, com Piaget, que cada ato de ensino priva uma oportunidade de descoberta, sugere que a atitude construcionista seja minimalista: que se tente obter o máximo de aprendizagem a partir de um mínimo de ensino. Mas alertando que essa atitude minimalista, quanto ao ensino, de pouco vale, se tudo o resto ficar como estava.

Colocando a questão de outra maneira, o construcionismo requer uma atitude inspirada num provérbio africano sobre a melhor maneira de ajudar alguém com fome: uma hipótese será dar-lhe um peixe, mas a hipótese redentora seria dar-lhe uma cana e ensiná-lo a pescar. É por isso que Papert considera que: 
A educação tradicional codifica o que pensa que os cidadãos precisam saber e parte para alimentar as crianças com esse "peixe". O construcionismo é construído sobre a suposição de que as crianças farão melhor descobrindo ("pescando") por si mesmas o conhecimento específico de que precisam; a educação organizada ou informal poderá ajudar mais se certificar-se de que elas estarão sendo apoiadas moral, psicológica, material e intelectualmente em seus esforços. O tipo de conhecimento que as crianças mais precisam é o que as ajudará a obter mais conhecimento. É por isso que precisamos desenvolver a matética (PAPERT, 2008, p. 135).

E, no que se refere concretamente à ideia de construção, continua:

O construcionismo também possui a conotação de "conjunto de peças para construção", iniciando com conjuntos no sentido literal, como o Lego, e ampliando-se para incluir linguagens de programação consideradas como "conjuntos" a partir dos quais programas podem ser feitos, até cozinhas como "conjuntos" com os quais são construídas não apenas tortas, mas receitas e formas de matemática-em-uso. Um dos meus princípios matéticos centrais é que a construção que ocorre "na cabeça" ocorre com frequência de modo especialmente prazeroso quando é apoiada por um tipo de construção mais pública, "no mundo" - um castelo de areia ou uma torta, uma casa Lego ou uma empresa, um programa de computador, um poema ou uma teoria do universo. Parte do que tenciono dizer com "no mundo" é que o produto pode ser mostrado, discutido, examinado, sondado e admirado. Ele está lá fora. (PAPERT, 2008, p. 137).
Como se depreende, o construcionismo enfatiza fortemente os objetos externos ao seu criador, que são realizações no mundo, que podem ser mostradas, discutidas, examinadas, provadas e admiradas. Assim, partilhar uma criação pode resultar, não apenas no seu refinamento, mas também na obtenção de uma compreensão mais profunda das perspetivas das outras pessoas.

Constructionism - the $\mathrm{N}$ word as opposed to the $\mathrm{V}$ word - shares constructivism's connotation of learning as a 'building knowledge structures' irrespective of the circumstances of the learning. It then adds that this happens especially felicitously in a context where the learner is consciously engaged in constructing a public entity, whether it's a sand castle on the beach or a theory of the universe... (PAPERT, 1991, p. 1).

Refira-se, finalmente, que, sendo a tecnologia um dos elementos mais versáteis para a criação de contextos de aprendizagem construcionistas (veja-se o caso dos micromundos criados a partir da linguagem Logo ou de outras tecnologias que lhe sucederam, como os kits Lego-Logo, o Scratch, etc.), não é o seu elemento mais crítico. $O$ construcionismo não é tecnocêntrico. Se lhe tivéssemos de identificar uma centralidade, ela não seria certamente a tecnologia, que não passa de uma ferramenta para o pensamento, mas a ação, a construção e a matética.

Concluindo, diria que o construcionismo é um exemplo de pedagogia que problematiza o uso da moderna tecnologia de uma maneira que está nos antípodas da didática escolar. Aliás, na perspetiva de Giroux, por exemplo, o uso das tecnologias como ferramentas pedagógicas nas escolas (Giroux utiliza a palavra pedagogia com um significado idêntico ao que tem no texto de Pinar) tem trazido, como subproduto, a diminuição do controlo da turma pela professores e a desumanização dessa mesma pedagogia.

One consequence of the use of a means driven technology as a pedagogical tool is 
that instrumental goals replace ethical and political considerations, diminishing classroom control by teachers while offering a dehumanizing pedagogy for students. (GIROUX, 2009, p. 685).

\section{4.}

Quer o construcionismo de Papert, quer a pedagogia do oprimido, de Freire, esta última visando "proporcionar, com os educandos, as condições em que se dê a superação do conhecimento no nível da "doxa" pelo verdadeiro conhecimento, o que se dá, no nível do "logos""' (FREIRE, 2010, p. 80), nada têm a ver com o universo da educação reduzido à didática e aos seus procedimentos. Ambas remetem para o que afirmo no editorial que abre o conjunto de reflexões de que este artigo faz parte, para uma conceção de pedagogia que extravasa da sala de aula para o mundo, como lugar onde se vive, e onde aprender é parte intrínseca da vida, elevando-se, por essa via, muito acima de um mero conjunto de procedimentos técnicos de ensino-aprendizagem.

Também costumo dizer que já sabemos praticamente tudo sobre didática, ficando a "surpresa" reduzida à maneira como a didática curricularizará o próximo gadget que vier a ser lançado no mercado, fazendo dele mais uma peça do mesmíssimo edifício escolar a que pertence. Em oposição, não sabemos ainda nada da próxima pedagogia, a qual só será mesmo pedagogia se for realmente nova. E é por essas e por outras que costumo sorrir quando ouço falar em investigar ou em linhas de investigação em didática, muito endossadas nomeadamente por algumas comissões de avaliação externa enviadas pela agência nacional de acreditação para avaliarem cursos de formação de professores, não vão esses cursos esquecer assunto tão relevante, ou promover ideias heréticas.

Mas não vou além de um sorriso amarelo quando o discurso educacional vigente confunde inovação pedagógica com incorporação dos novos gadgets para serem utilizados como recursos didáticos. É que, por muito que a didática incorpore tecnologia e se apoie nas mais sofis- ticadas teorias da comunicação, será sempre um conjunto de técnicas e um projeto de simplificação, de que um dos exemplos mais flagrantes é a substituição do texto pelo livro de texto, como diria Hamilton $(1993)^{6}$. Nunca será pedagogia.

E não é verdade, pelo menos em Portugal, que os estudos curriculares tenham alguma vez inflacionado o papel da pedagogia, ainda que concorde que talvez discutam o professor em demasia, nomeadamente o que ele faz e como faz, em detrimento óbvio da atenção que deveriam dar à atividade dos aprendizes, aos contextos de aprendizagem e aos processos matéticos. Pelo contrário, o que sempre esteve empolado foi a didática e os seus procedimentos. Portanto, e para meu desgosto, o que julgo poder ser constatado é que os estudos curriculares têm pedagogia a menos, embora imagine que talvez a pedagogia seja imensamente menos curricularizável do que a didática.

\section{Notas}

1 Professor Catedrático (Full Professor). Presidente da Faculdade de Ciências Sociais e responsável pela linha de pesquisa em inovação pedagógica do Centro de Investigação em Educação (CIE-UMa) da Universidade da Madeira, Portugal. cfino@staff. uma.pt

2 Edição eletrónica, disponível em http://www.ebooksbrasil. org/eLibris/didaticamagna.html.

${ }^{3}$ Uso, como referência, o ano de 1960, data do lançamento do sistema PLATO (Programmed Logic for Automatic Teaching Operations), criado por Donald L. Bitzer da Universidade do Illinois. O funcionamento do sistema PLATO tem evidentes semelhanças com o funcionamento das máquinas de instrução programada, de Skinner.

${ }^{4}$ By contrast, pedagogics is not an alien notion to Anglo-American educationalists. It re-entered the Anglo-American educational lexicon after 1970, having lain dormant since the First World War (cf. Cruikshank, 1998). The 1970s revival, however, was not a restatement of earlier assumptions. Rather, fresh meanings arose that, paradoxically, have hindered transatlantic dialogue. The European discourse of didactics is, I suggest, very close to the Anglo-American discourse of pedagogics. Only their language divides them. (HAMILTON, idem, ibidem).

${ }^{5}$ A partir da publicação do Decreto-Lei de 2007, as universidades, se assim o entendessem, ainda poderiam formar professores de acordo com as suas perspetivas. No entanto, se a formação não seguisse o que estava legislado, esses candidatos não 
seriam aceites nos concursos nacionais de acesso à carreira. Mais tarde, com o início do processo de acreditação dos cursos pela agência nacional, nem essa possibilidade teórica seria possível, uma vez que a agencia não acreditaria nenhum curso que não estivesse de acordo com o diploma. Tal significa que um diploma do Ministério da Educação, que tutelava o ensino não superior, derrogou a autonomia universitária no que se refere à formação de professores, sendo que o ensino superior era tutelado, na época, pelo Ministério da Ciência e Ensino Superior.

${ }^{6}$ Textbooks, therefore, are not simply depositories of knowledge. Through their chapters, headings, tables, illustrations, worked examples, homework exercises, and so on, they mediate the structure of knowledge on the one hand, and the performance of teaching and learning on the other. They are a condensation, therefore, of both knowledge and instruction (HAMILTON, 2003, p. 08).

\section{Referências}

COMENIUS, Iohannis Amos. Didactica Magna. Tradução de Joaquim Ferreira Gomes. Edição digital da Fundação Calouste Gulbenkian, 2001. Disponível em http://www.ebooksbrasil.org/ eLibris/didaticamagna.html. Acesso em 21 de julho de 2017.

FREIRE, Paulo. Pedagogia do Oprimido [49a Reimpressão]. Rio de Janeiro: Paz e Terra, 2010.

GIROUX, Henry. Democracy's Nemesis - The Rise of the Corporate University. Cultural Studies - Critical Methodologies, vol. 9, 5: pp. 669-695, 2009.

HAMILTON, David. Instruction in the making: Peter Ramus and the beginnings of modern schooling. American Educational Research Association, Chicago, April, 2003. Disponível em http://www.leeds.ac.uk/educol/documents/152133.htm. Acesso em 21 de julho de 2017.

HAMILTON, David. The pedagogic paradox (or why no didactics in England?), Pedagogy, Culture \& Society, 7:1, 135-152, 1999.

PAPERT, Seymour. Situating Constructionism. In: HAREL, I.; PAPERT, S. (Ed.), Constructionism. Norwood, NJ: Ablex Publishing, 1991, pp. 1-12.

PAPERT, Seymour. A Máquina das Crianças - repensando a escola na era da informática. Porto Alegre: Artmed, 2008.

PINAR, William F..The Problem with Curriculum and Pedagogy. Journal of Curriculum and Pedagogy Vol. 2 , Iss. 1, 2005.

SIMON, Brian. Why no pedagogy in England. In: SIMON, B.; TAYLOR, W. (eds.) Issues for the 80's. London: Batsford, 1981. 
